1 Universidade Federal de Mato Grosso (UFMT), Instituto de Saúde Coletiva (ISC) - Cuiabá (MT),

Brasil.

marcialmontanari@gmail.

com

2 Fundação Oswaldo Cruz (Fiocruz) - Brasília (DF), Brasil.

\section{Alimento ou mercadoria? Indicadores de autossuficiência alimentar em territórios do agronegócio, Mato Grosso, Brasil}

\author{
Food or commodity? Indicators of food self-sufficiency in \\ Agribusiness territories, Mato Grosso, Brazil
}

Marcia Leopoldina Montanari Corrêa', Wanderlei Antônio Pignati', Marta Gislene Pignatti1, Jorge

Mesquita Huet Machado², Francco Antonio Neri de Souza e Lima1

DOI: 10.1590/0103-1104201912307

RESUMO O uso da terra para produção de commodities agrícolas em municípios do agronegócio mato-grossense vem ocupando espaço de produção de alimentos. O objetivo deste estudo foi apresentar e discutir um indicador composto de avaliação da autossuficiência na produção de alimentos em interface com as implicações do modelo produtivo do agronegócio, na perspectiva da soberania alimentar dos territórios, baseado no estudo de caso realizado nos municípios de Campos de Júlio, Sapezal e Campo Novo dos Parecis. Os dados socioeconômicos foram levantados a partir do Censo Demográfico do Instituto Brasileiro de Geografia e Estatística - IBGE/2010, Perfil dos Estados e dos Municípios Brasileiros/IBGE, 2014, e Censo Agropecuário de 2006. Para levantamento de produção, utilizaram-se dados disponíveis no Sistema IBGE de Recuperação Automática (Sidra) para o ano de 2016. Obtiveram-se informações acerca de área plantada das culturas de algodão, arroz, banana, café, cana-de-açúcar, citrus, feijão, girassol, milho, soja, tomate. Foram realizadas entrevistas com trabalhadores rurais e horticultores. A partir dos dados, foram elaborados indicadores compostos para a proposição de uma escala de autossuficiência alimentar nos territórios estudados. Os resultados apontam para desigualdades na ocupação dos territórios, dependência de alimentos de outras regiões e aumento do uso de agrotóxicos como consequência do modelo de produção adotado, afetando a produção local de alimentos.

PALAVRAS-CHAVE Produção de alimentos. Abastecimento de alimentos. Saúde ambiental.

\begin{abstract}
The land use for the production of agricultural commodities in municipalities of the agribusiness in Mato Grosso state has been occupying space for food production. The objective of this study was to present and discuss a composite indicator of self-sufficiency assessment in the production offood in interface with the implications of the agribusiness productive model, in the perspective of the food sovereignty of the territories, based on a case study carried out in the counties Campos de Júlio, Sapezal and Campo Novo dos Parecis. Socioeconomic data were collected based on the IBGE/2010 Demographic Census, Profile of Brazilian States and Municipalities/IBGE (Brazilian Institute of Geography and Statistics), 2014, and the Agricultural Census of 2006. For production survey, data available in the IBGE System of Automatic Recovery (Sidra) were used for the year of 2016. Informations were obtained on the cultivated area of cotton, rice, banana, coffee, sugarcane, citrus, beans, sunflower, corn, soybean, tomato. Interviews were conducted with rural workers and horticulturists. Based on the data, composite indicators were developed for proposing a food self-sufficiency scale in the territories studied. The results point to iniquities in the occupation of the territories, dependence on food from other regions and increased use of pesticides as a consequence of the adopted production model, affecting local food production.
\end{abstract}

KEYWORDS Food production. Food supply. Environmental health. 


\section{Introdução}

A dinâmica produtiva agrícola de um espaço interfere na organização social do território, especialmente com relação à produção de alimentos para abastecimento local ou exportação. Essas questões estão diretamente relacionadas à economia, à política governamental e à inserção ou não da participação das pessoas no controle dos sistemas alimentares. O termo soberania alimentar é definido como o direito das nações e dos povos de controlar seus próprios sistemas alimentares, seus próprios mercados, a escolha dos modelos produtivos, culturas e ambientes de alimentos ${ }^{\mathbf{1}}$, enquanto o conceito de segurança alimentar e nutricional abarca a realização do direito de todos ao acesso permanente a alimentos de qualidade, em quantidade suficiente, sem comprometer o acesso a outras necessidades essenciais, pautado em práticas alimentares promotoras de saúde, que respeitem a diversidade cultural e que sejam social, econômica e ambientalmente sustentáveis ${ }^{2}$.

A complementariedade entre os conceitos se expressa pelas formas de produção e obtenção dos alimentos com dinâmicas e repercussões locais. Nesse sentido, o conceito de autossuficiência alimentar aqui discutido implica a capacidade de produzir alimentos para abastecimento local e regional, respeitando-se a adoção de modelos de produção alternativos ao hegemônico do agronegócio, de forma que não se sobreponham os interesses econômicos globais às necessidades locais de abastecimento, proteção dos ambientes e da saúde das pessoas.

A promoção da soberania alimentar de um território requer a garantia do acesso à terra e às condições necessárias ao fortalecimento da produção familiar e dos mercados locais. De acordo com o Plano Nacional de Segurança Alimentar e Nutricional 2016-2019, o fomento à agricultura familiar garante a diminuição da pobreza e da desigualdade no meio rural, uma maior diversificação na produção de alimentos, o fortalecimento do abastecimento alimentar em localidades distantes e a consequente dinamização das economias locais ${ }^{3}$.

Estudos de Insegurança Alimentar a partir de indicadores como a Ebia (Escala Brasileira de Medida da Insegurança Alimentar) têm sido realizados no Brasil desde a sua validação, em 2003, e posterior inclusão na Pesquisa Nacional por Amostra de Domicílio (PNAD)/ Instituto Brasileiro de Geografia e Estatística (IBGE) 2004, sendo considerado instrumento para a geração de indicador direto de medida domiciliar de segurança alimentar ${ }^{4}$. Ainda que essa medida seja um importante indicador, entende-se que a segurança alimentar de um território vai além da garantia do acesso aos alimentos, mas contempla a equidade no uso dos territórios e na definição dos modelos de produção, buscando garantir a justiça social e a promoção da saúde.

Contrariando essa perspectiva, o agronegócio representa uma estratégia de expansão do capital agroindustrial, que se consolidou como modelo hegemônico a partir de um discurso de ampliação da produção mundial de alimentos no período pós-guerra, sobretudo a partir da década de 1950, com a denominada Revolução Verde, cujas bases de sustentação impuseram ao campo a modernização e a tecnificação da agricultura ${ }^{5}$. Esse modelo de produção acompanha as tendências de padronização e homogeneização alimentar e atende a perfis de consumo da sociedade pós-moderna ${ }^{6}$, cuja base está no ultraprocessamento de alimentos, na obtenção de proteínas de origem animal e de combustíveis.

O Brasil é, atualmente, um dos maiores exportadores de commodities mundiais e mantém sua economia dependente desse modelo produtivo ${ }^{7}$, que traz consequências pela super exploração dos recursos naturais e do trabalho ${ }^{8}$, concentra terras e capitais 9 , vulnerabiliza as populações camponesas e tradicionais pelo processo de 'pressão' e 'expulsão' de suas terras ${ }^{5,8}$, traz consequências à saúde das pessoas ${ }^{10,11}$ e à soberania alimentar dos territórios ${ }^{\mathbf{1 2 , 1 3}}$. Por outro lado, os alimentos que abastecem as populações urbanas provêm, 
em grande parte, da produção familiar, cujo potencial de produção policultural, orgânica e agroecológica carece de políticas públicas de incentivo e subsídios ${ }^{13,14}$.

O estado de Mato Grosso se transformou nas últimas décadas em uma região estratégica para a expansão do agronegócio com a utilização de extensas áreas para produção de monoculturas sobre o bioma cerrado. Mato Grosso apresenta grandes regiões produtivas de lavouras ${ }^{15}$, entre as quais destacam-se os municípios de Campos de Julio, Sapezal e Campo Novo do Parecis, que compõem a Bacia do Rio Juruena, em cujo território coexistem áreas de monocultivos, Terras Indígenas e importantes rios que vão compor a Bacia do Rio Amazonas. Por sua área plana e clima ameno, essas terras têm sido utilizadas intensamente para a agricultura mecanizada e produção de commodities agrícolas, em detrimento da produção de alimentos.

O presente artigo tem o objetivo de apresentar e discutir um indicador composto de avaliação da autossuficiência na produção de alimentos em interface com as implicações do modelo produtivo do agronegócio na perspectiva da soberania alimentar dos territórios, tendo como base um estudo de caso realizado em três municípios da Bacia do Rio Juruena, em Mato Grosso. Entende-se que a ocupação hegemônica de um modelo produtivo cujo objetivo principal é a produção de commodities para exportação concentra e centraliza o capital, comprometendo os espaços de produção e reprodução dos agricultores familiares, dificultando aos consumidores locais e o acesso aos alimentos produzidos sem a utilização de insumos químicos.

A análise de indicadores locais de autossuficiência alimentar possibilita evidenciar a ocupação do território destinado à produção local e regional, contribuindo para uma análise mais ampliada da segurança alimentar e sua interface com a promoção de saúde. Não se trata de discutir apenas o acesso e a disponibilidade do alimento, mas as estratégias de produção e abastecimento local que caracterizam esse acesso de forma democrática e ambientalmente sustentável, respeitando a autonomia dos povos na definição de seus sistemas alimentares, bem como ampliando o acesso seguro a alimentos saudáveis, um dos pilares do direito humano à alimentação adequada e da promoção da saúde.

\section{Métodos}

Trata-se de um estudo de caso avaliativo que integra técnicas de pesquisa qualitativa e análise de dados secundários de produção e ocupação do território para compor uma matriz de indicadores, a partir da qual se estabeleceu um indicador composto de autossuficiência para a soberania alimentar, realizado nos municípios de Campos de Júlio, Campo Novo do Parecis e Sapezal, localizados no Oeste do estado de Mato Grosso.

\section{Entrevistas}

Foram realizadas entrevistas com 05 trabalhadores rurais e 02 horticultores, contatados pelo Sindicato dos Trabalhadores Rurais em Campo Novo dos Parecis; 20 trabalhadores rurais e 02 horticultores em Campos de Júlio; e 05 horticultores em Sapezal, totalizando 34 entrevistas. As entrevistas ocorreram entre os anos de 2015 e 2016, transcritas e analisadas pela perspectiva de 'Análise do Conteúdo'16. Entre os entrevistados que compõem a categoria 'trabalhador rural', 20 são assentados (80\%) e 05 possuem vínculo trabalhista formal em fazendas da região (20\%). Entre os horticultores entrevistados, todos são proprietários de terrenos localizados no entorno da área urbana das cidades. A faixa etária média foi de 42 anos, sendo a maioria ( $85 \%$ ) do sexo masculino.

O roteiro de entrevistas foi composto das seguintes questões: O Sr./Sra. produz aqui nesta propriedade? Quais alimentos?; $\mathrm{O} \mathrm{Sr}$./ Sra. é vinculado a algum movimento social ligado à luta pela terra ou sindicato?; O Sr./ Sra. comercializa seus produtos em feiras, 
mercados públicos, bancas, supermercados no município/região? Como é feita a comercialização?; O Sr./Sra. comercializa seus produtos para instituições? Quais? Por meio de quais programas?; Na sua opinião, quais são as dificuldades na produção de alimentos aqui na região? E quais são os pontos positivos?; O Sr./Sra. sabe de onde vêm os alimentos que abastecem o município?; Quais são as suas sugestões para melhorar a produção de alimentos no município/região?

Seguindo as etapas propostas por Bardin, foi iniciada a transcrição, pré-análise, exploração do material; tratamento dos dados, interpretação e inferências ${ }^{16}$. A partir da leitura das entrevistas, foram identificadas as seguintes categorias de análise: Dificuldades na Produção de Alimentos para consumo e comercialização local/regional; Dificuldades de comercialização em mercados locais/regionais; Dependência de alimentos produzidos em outras regiões para abastecimento local; Inequidades na Ocupação dos territórios. Foram também identificados os locais de produção, caracterizados como 'produção para abastecimento local/regional' e 'produção de commodities agrícolas' nos municípios.

\section{Produção agrícola e utilização de agrotóxicos}

Para a realização do levantamento de produção, utilizaram-se como base os dados de área plantada por cultivo obtidos pela Produção Agrícola Municipal (PAM) do banco de dados do Sistema IBGE de Recuperação Automática (Sidra) para o ano de 2016 ${ }^{17}$. Obtiveram-se informações acerca de área plantada das culturas de algodão, arroz, banana, café, cana-de-açúcar, citrus, feijão, girassol, milho, soja, tomate. Essas culturas foram escolhidas por representarem o perfil predominante de produção no estado e para efeito de comparação com os alimentos mais frequentemente consumidos na dieta nacional ${ }^{18}$.

Os locais destinados à produção local/ regional que denominam os espaços de produção e/ou venda direta ao consumidor, tais como hortas, feiras, laticínios, pesqueiros, entre outros, foram informados durante as entrevistas. Os dados de utilização de agrotóxicos foram estimados conforme metodologia proposta por Pignati et al. ${ }^{19}$, a partir da área plantada de cada produto e média de utilização de agrotóxicos por cultura agrícola.

\section{Construção dos indicadores}

Os dados representam eventos da realidade empiricamente observáveis e percepções de atores sociais sobre tal realidade, e são a matéria-prima da produção de indicadores, cujo objetivo é estruturar sistemas de monitoramento de uma determinada situação ambiental e alimentar com a vigilância sobre os determinantes e condicionantes da exposição das populações aos riscos à saúde ${ }^{20}$. Apesar de sua importância, os indicadores não abrangem a totalidade da realidade, mas permitem a identificação de áreas prioritárias, o monitoramento de situações de risco e a comparação entre diferentes territórios, subsidiando a tomada de decisão.

A partir dos dados coletados, foram propostos indicadores, seus respectivos valores de referência e uma escala para análise de autossuficiência alimentar, sob a perspectiva da soberania alimentar, conforme apresentado no quadro 1: 
Quadro 1. Indicadores propostos para análise de autossuficiência alimentar em territórios do agronegócio em MT

\begin{tabular}{|c|c|c|c|c|}
\hline Indicador & Fórmula & Fonte & Valores de Referência & Escala \\
\hline \multirow{3}{*}{$\begin{array}{l}\text { \% território destinado à } \\
\text { produção de commodities } \\
\text { (soja, algodão, cana, gi- } \\
\text { rassol) }\end{array}$} & \multirow{3}{*}{$\begin{array}{l}\text { Área plantada em hectares/área } \\
\text { total de produção do município } \\
\text { × } 100\end{array}$} & \multirow{3}{*}{$\begin{array}{l}\text { IBGE-Sidra } \\
\text { Dados de Produção } \\
\text { Agrícola Municipal }\end{array}$} & $0-25 \%$ & 1 \\
\hline & & & $25 \%-75 \%$ & 2 \\
\hline & & & $75 \%-100 \%$ & 3 \\
\hline \multirow{3}{*}{$\begin{array}{l}\text { \% território destinado à } \\
\text { produção de alimentos } \\
\text { (arroz, feijão, café, tomate, } \\
\text { abacaxi, banana, citrus) }\end{array}$} & \multirow{3}{*}{$\begin{array}{l}\text { Área plantada em hectares/área } \\
\text { total de produção do município } \\
\text { × } 100\end{array}$} & \multirow{3}{*}{$\begin{array}{l}\text { IBGE-Sidra } \\
\text { Dados de Produção } \\
\text { Agrícola Municipal }\end{array}$} & $0-25 \%$ & 3 \\
\hline & & & $25 \%-75 \%$ & 2 \\
\hline & & & $75 \%-100 \%$ & 1 \\
\hline \multirow{3}{*}{$\begin{array}{l}\text { Presença de espaços de } \\
\text { produção e/ou venda direta } \\
\text { de alimentos ao consu- } \\
\text { midor }\end{array}$} & \multirow{3}{*}{$\begin{array}{l}\text { Presença de feiras, hortas, } \\
\text { pesqueiros, laticínios, granjas, } \\
\text { farinheiras, pomares }\end{array}$} & \multirow{3}{*}{$\begin{array}{l}\text { Entrevistas e dados } \\
\text { do Instituto de } \\
\text { Defesa Agropecuá- } \\
\text { ria de Mato Grosso } \\
\text { (Indea-MT) }\end{array}$} & $\begin{array}{l}\text { - Presença de pelo } \\
\text { menos } 02 \text { itens; }\end{array}$ & 1 \\
\hline & & & $\begin{array}{l}\text { - Presença de hortas } \\
\text { apenas; }\end{array}$ & 2 \\
\hline & & & - Ausência & 3 \\
\hline \multirow[t]{3}{*}{$\begin{array}{l}\text { Utilização de agrotóxicos } \\
\text { por ano }\end{array}$} & \multirow{3}{*}{$\begin{array}{l}\text { Estimativa de consumo de agro- } \\
\text { tóxicos proposta por Pignati et } \\
\text { al., 2017, com base nos dados } \\
\text { do Indea-MT }\end{array}$} & \multirow{3}{*}{$\begin{array}{l}\text { Volume de agrotó- } \\
\text { xicos utilizados por } \\
\text { ano (litros) }\end{array}$} & $\begin{array}{l}\text { Entre } 100 \text { litros e } \\
1.999 .999 \text { litros }\end{array}$ & 1 \\
\hline & & & $\begin{array}{l}\text { Entre } 2.000 .000 \text { e } \\
5.000 .000 \text { litros }\end{array}$ & 2 \\
\hline & & & $\begin{array}{l}\text { Acima de } 5.000 .000 \\
\text { litros }\end{array}$ & 3 \\
\hline \multirow{6}{*}{$\begin{array}{l}\text { Percepção de Trabalhadores } \\
\text { rurais sobre produção local/ } \\
\text { regional de alimentos }\end{array}$} & \multirow{2}{*}{$\begin{array}{l}\text { - Dificuldade na Produção } \\
\text { Local/regional de alimentos }\end{array}$} & \multirow{6}{*}{$\begin{array}{l}\text { Categorias levanta- } \\
\text { das nas entrevistas } \\
\text { com trabalhadores } \\
\text { rurais e pequenos } \\
\text { produtores (horti- } \\
\text { cultores) }\end{array}$} & Não & 0 \\
\hline & & & Sim & 1 \\
\hline & \multirow{2}{*}{$\begin{array}{l}\text { - Inequidades na Ocupação dos } \\
\text { territórios; }\end{array}$} & & Não & 0 \\
\hline & & & Sim & 1 \\
\hline & \multirow{2}{*}{$\begin{array}{l}\text { - Dependência de alimentos } \\
\text { produzidos em outras regiões }\end{array}$} & & Não & 0 \\
\hline & & & Sim & 1 \\
\hline
\end{tabular}

Fonte: Elaboração própria com base nos dados de Produção Agrícola Municipal IBGE/Sidra17; Pignati et al. 201719 e nas entrevistas.

O objetivo da escala é analisar a ocupação do território com relação à produção local e produção de commodities. Com base na somatória dos valores de referência equivalentes a cada indicador analisado, foram utilizados os seguintes escores:

- 1 a 5 pontos: A produção de commodities e alimentos ocorre concomitante;

- 5 a 10 pontos: A produção local/regional de alimentos é restrita;

- 10 a 15 pontos: A produção local/regional de alimentos é inviabilizada pela produção de commodities, afetando a soberania alimentar do território.

Utilizou-se o software Excel 2010 para a elaboração das tabelas, e ArcGis 10.1, da Esri, para elaboração dos mapas.

A pesquisa foi submetida ao Comitê de Ética em pesquisas envolvendo seres humanos do Hospital Universitário Júlio Muller, tendo sido aprovada em 08/02/2015, sob parecer $\mathrm{n}^{\circ} 951.083$.

\section{Resultados}

A partir de alguns indicadores considerados sentinela para analisar o território, foi construída uma escala de referência, baseada nos dados de produção, na utilização de agrotóxicos e na categorização das entrevistas realizadas nos municípios.

Os dados disponíveis na tabela 1 indicam que a produção nos municípios estudados se concentra nas commodities agrícolas (soja, algodão, cana-de-açúcar, milho e 
girassol), em detrimento de produtos agrícolas mais frequentes da dieta nacional, tais como arroz, feijão, café, banana e tomate.

Tabela 1. Área destinada à Produção Agrícola Municipal por hectares das principais culturas

\begin{tabular}{|c|c|c|c|c|c|c|c|}
\hline Categoria & Cultura (ha) & $\begin{array}{r}\text { C. N. Parecis } \\
\text { (A) }\end{array}$ & $\begin{array}{r}\text { Campos de } \\
\text { Julio (B) } \\
\end{array}$ & Sapezal (C) & $\begin{array}{r}\text { Total na região } \\
(\mathrm{A}+\mathrm{B}+\mathrm{C}) \\
\end{array}$ & Mato Grosso & $\begin{array}{l}\text { Área plantada/cultura na } \\
\text { região em relação a MT (\%) }\end{array}$ \\
\hline \multirow[t]{6}{*}{ Commodities } & Algodão & 48.581 & 27.496 & 128.469 & 204.546 & 606.314 & 33,70 \\
\hline & Cana & 34.661 & 9.100 & 0 & 43.761 & 280.191 & 15,60 \\
\hline & Girassol & 15.830 & 860 & 1.985 & 18.675 & 29.122 & 64 \\
\hline & Milho & 146.800 & 129.036 & 153.000 & 428.836 & 3.900 .268 & 11 \\
\hline & Soja & 380.000 & 186.079 & 368.368 & 934.447 & 9.147 .863 & 10 \\
\hline & $\%$ & $98 \%$ & $97 \%$ & $99 \%$ & $98 \%$ & $97 \%$ & --- \\
\hline \multirow[t]{4}{*}{ Grãos* } & Arroz & 0 & 810 & 0 & 810 & 174.263 & 0,46 \\
\hline & Café & 0 & 0 & 0 & 0 & 16.293 & 0 \\
\hline & Feijão & 13.440 & 9.768 & 8.250 & 31.458 & 251.672 & 12,50 \\
\hline & $\%$ & $2 \%$ & $3 \%$ & $1,2 \%$ & $2 \%$ & $3 \%$ & --- \\
\hline \multirow{5}{*}{$\begin{array}{l}\text { Hortaliças e } \\
\text { Frutas }^{\star \star}\end{array}$} & Abacaxi & 1 & 0 & 0 & 1 & 1.449 & 0,07 \\
\hline & Banana & 0 & 0 & 0 & 0 & 6.967 & 0 \\
\hline & Citrus & 0 & 0 & 0 & 0 & 937 & 0 \\
\hline & Tomate & 0 & 0 & 0 & 0 & 243 & 0 \\
\hline & $\%$ & 0 & 0 & 0 & 0 & $0,07 \%$ & --- \\
\hline \multicolumn{2}{|l|}{ Totais } & 639.313 & 363.149 & 660.072 & 1.662 .534 & 14.418 .300 & 11,50 \\
\hline
\end{tabular}

A região disponibiliza cerca de $98 \%$ de seu território à produção de commodities agrícolas e $2 \%$ do território para produção de alimentos, seguindo a tendência do estado de Mato Grosso de reprimarização da economia. Em 2016, o Mato Grosso produziu 27\% da soja brasileira, em 9,1 milhões de hectares; 24\% do milho em 3,9 milhões hectares; 63,5\% do algodão em 606 mil hectares; $2,5 \%$ da cana de açúcar em 280 mil hectares; $54 \%$ do Girassol em 29 mil hectares; e 20 milhões de hectares de pastagem, com 30 milhões de bovinos ${ }^{15,17 .}$

Conforme dados do Censo Agropecuário $2006^{15}$, a maioria dos estabelecimentos rurais na região pertence a grandes proprietários individuais e a consórcios de grupos agropecuários, uma média de 95\% das áreas destinadas à produção dos municípios, quando comparados com assentados, ocupantes e parceiros, expressando a concentração dos latifúndios. Portanto, a produção local de alimentos é realizada por pequenos proprietários que dispõem de terrenos no entorno dos municípios ou na área urbana para plantio de hortas ou produção de pescados. Em geral, as hortas ficam localizadas na região central das áreas urbanas dos municípios devido à distância das lavouras, o que possibilita a produção de hortaliças.

A comparação entre os censos agropecuários de $2006^{15}$ e os dados preliminares do Censo $2017^{21}$ ilustra essa situação a partir do aumento de $5 \%$ da área plantada em hectares, 
apesar da redução de $2 \%$ no número de estabelecimentos rurais, com destaque para o aumento de estabelecimentos com 1000 hectares acima, cuja participação relativa na área total passou de $45 \%$ para $47,5 \%$ de 2006 para 2017, e redução de estabelecimentos entre 100 e 1000 hectares com queda na participação relativa na área total de $33,8 \%$ para $32 \%$, o que indica a concentração das terras para grupos agropecuários em detrimento de pequenos e médios produtores.

Os municípios estão entre os que apresentam maior área plantada em MT, conforme é possível observar na figura 1.

Figura 1. Mapa de área plantada e utilização de agrotóxicos em Mato Grosso, 2016
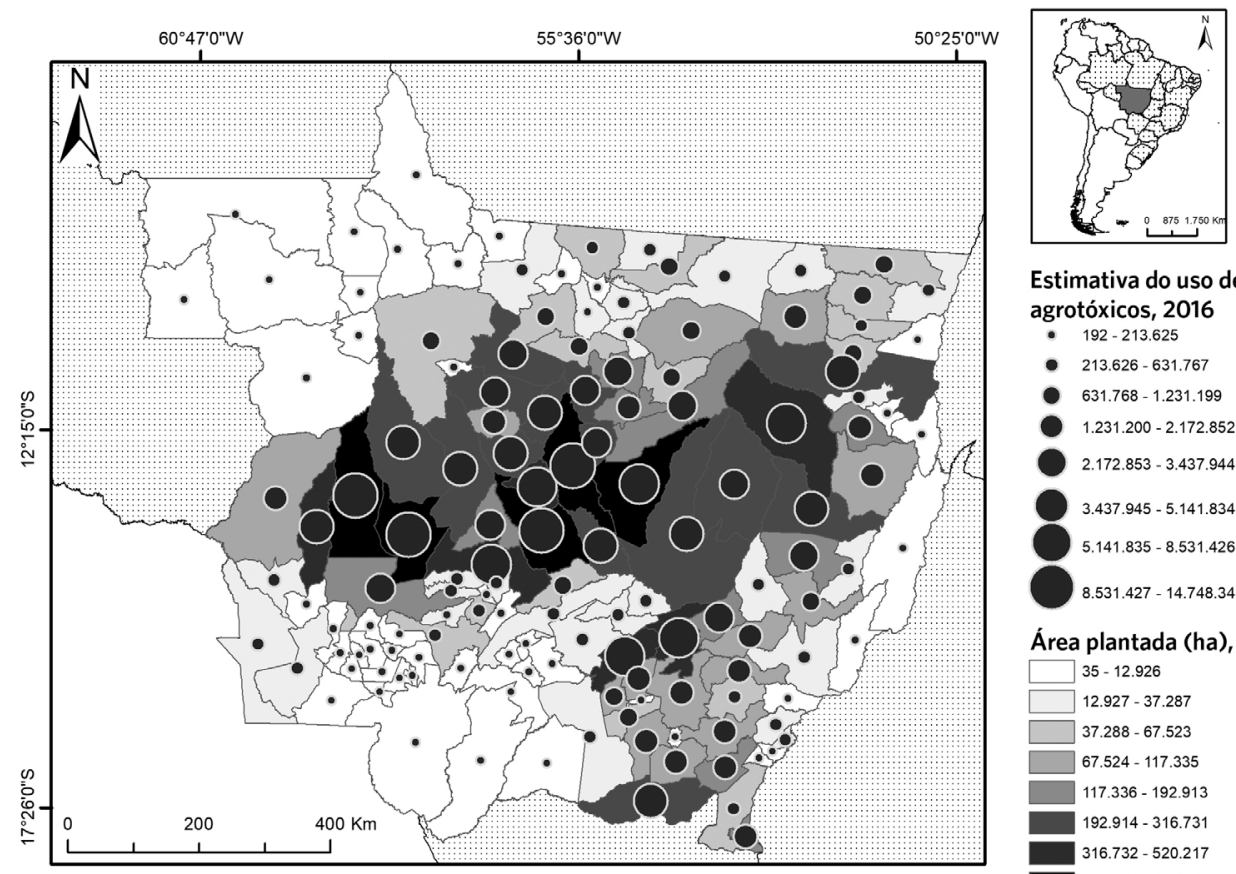

Estimativa do uso de agrotóxicos, 2016 - $192-213.625$

- $213.626-631.767$

- $631.768-1.231 .199$

$1.231 .200-2.172 .852$

$2.172 .853-3.437 .944$

$3.437 .945-5.141 .834$

$5.141 .835-8.531 .426$

$8.531 .427-14.748 .348$

Área plantada (ha), 2016

$\square$
$\square-12.926$

$\square 12.927-37.287$

$\square 7.288-67.523$

$67.524-117.335$

$\square 117.336-192.913$

$192.914-316.731$

$520.218-1.105 .188$

Fonte: IBGE/Sidra, 201617; Pignati et al., 201719, atualizado pelos autores.

Para cada hectare plantado na região, utilizam-se, em média, 10 a 20 litros de agrotóxicos, o que coloca esses municípios entre os maiores consumidores de agrotóxicos do estado. Considerando o perfil de produção dos municípios, esses valores aumentam de acordo com a cultura plantada, uma vez que, para lavouras de algodão, são utilizados em média 28 litros por hectare, e, para soja, 17,7 litros de agrotóxico por hectare ${ }^{19}$.

Em épocas de pulverização em aérea de agrotóxicos próxima da área urbana dos municípios, a produção de hortaliças é atingida e impactada, ocasionando perda da produção. Essa situação foi relatada pelos entrevistados nos três municípios estudados. Pignati, Machado e Cabral22 analisaram 'a chuva de agrotóxicos’ sobre o município de Lucas do Rio Verde/MT, na perspectiva de acidente rural ampliado. A utilização de tratores e aviões agrícolas para pulverização traz como consequência a deriva das névoas de agrotóxico, que, além de atingirem o alvo (plantas e pragas), também atingem os trabalhadores 
e, indiretamente, o ar/solo/água, os moradores, os animais e outras plantas que estão no entorno das 'áreas tratadas'22.

Entre os fatores de insegurança alimentar elencados nas entrevistas, as categorias identificadas foram: dificuldades na produção e comercialização local de alimentos; inequidades na ocupação dos territórios; dependência de alimentos produzidos em outras regiões. Os relatos apontam preocupação com o perfil de produção dos municípios e ausência de 'vontade política', manifestada na condução das políticas de fortalecimento da agricultura familiar, além das pressões para obtenção de 'pacotes tecnológicos', que acabam por levar o produtor a optar pela produção de commodities.

A predominância de lavouras de monoculturas nas áreas de entorno dos municípios dificulta a produção familiar/comunitária e policultural por diversos fatores, entre eles, a própria dificuldade de obtenção de terras e as pulverizações de agrotóxicos, que geram contaminações ambientais, restringindo e até mesmo inviabilizando a produção de alimentos. Tal fato evidencia as desigualdades do acesso e uso da terra e a dependência de mercados externos para prover o abastecimento das cidades.

Os relatos indicam, ainda, a baixa disponibilidade de alimentos provenientes da produção local, tais como frutas, hortaliças, frango, carne suína e leite, e a ausência de espaços destinados à comercialização ou ao processamento de alimentos da agricultura familiar na região, dificultando, inclusive, o cumprimento dos mecanismos de comercialização do PAA (Programa de Aquisição de Alimentos), que favorecem a aquisição direta de produtos de agricultores familiares ou de suas organizações para prover, entre outros, o abastecimento da rede escolar, conforme preconiza o Programa Nacional de Alimentação Escolar (PNAE) ${ }^{\mathbf{2 3}}$.

A dependência de alimentos de outros estados também é apontada como uma fragilidade, pela reduzida diversidade na oferta de alimentos, preços elevados e desconhecimento sobre a origem e o rastreamento dos alimentos que abastecem os municípios. Ao contrário da inexpressiva ocupação do território, com espaços destinados à produção e à comercialização de alimentos, muitos empreendimentos da cadeia do agronegócio se instalam nos municípios, com destaque para as algodoeiras, unidades de processamento de soja, silos, usinas de produção sucroalcooleira e usinas de produção de etanol de milho, cujos investimentos têm sido ampliados em municípios de Mato Grosso.

A escala de indicadores, disponível na tabela 2, aponta para um cenário de ocupação desigual dos territórios de produção dos municípios.

Tabela 2. Escala de indicadores para análise de ocupação do território na perspectiva da soberania alimentar

\begin{tabular}{|c|c|c|c|c|c|c|c|c|}
\hline \multirow[t]{2}{*}{ Municípios } & \multicolumn{2}{|c|}{$\begin{array}{r}\text { Área destinada } \\
\text { à produção de } \\
\text { Commodities (A) }\end{array}$} & \multicolumn{2}{|c|}{$\begin{array}{r}\text { Área destinada à } \\
\text { produção de Alimentos } \\
\text { (B) }\end{array}$} & \multirow{2}{*}{$\begin{array}{r}\text { Espaços } \\
\text { Produção e/ou } \\
\text { venda direta ao } \\
\text { consumidor (C) } \\
\text { Valor de } \\
\text { referência }\end{array}$} & \multirow{2}{*}{$\begin{array}{r}\text { Volume de } \\
\text { agrotóxicos } \\
\text { utilizados } \\
\text { (D) } \\
\text { Valor de } \\
\text { referência }\end{array}$} & \multirow{2}{*}{$\begin{array}{r}\text { Percepção de } \\
\text { trabalhadores rurais } \\
\text { quanto à produção local } \\
\text { de alimentos }(E) \\
\text { Valor de referência }\end{array}$} & \multirow{2}{*}{$\begin{array}{r}\text { Total }^{\star} \\
(A+B+C+D+E)\end{array}$} \\
\hline & $\%$ & $\begin{array}{l}\text { Valor de } \\
\text { referência }\end{array}$ & $\%$ & $\begin{array}{r}\text { Valor de } \\
\text { referência }\end{array}$ & & & & \\
\hline Campos de Júlio & 97 & 3 & 3 & 3 & 1 & 2 & 1 & 10 \\
\hline $\begin{array}{l}\text { Campo Novo dos } \\
\text { Parecis }\end{array}$ & 98 & 3 & 2 & 3 & 1 & 2 & 2 & 11 \\
\hline Sapezal & 99 & 3 & 1,2 & 3 & 2 & 3 & 3 & 14 \\
\hline
\end{tabular}

Fonte: Elaboração própria.

*1 a 5 pontos: A produção de commodities e alimentos ocorre concomitantemente; 6 a 10 pontos: A produção local/regional de alimentos é restrita; 11 a 15 pontos: A produção local/regional de alimentos é inviabilizada pela produção de commodities, afetando a soberania alimentar do território. 
Os municípios de Campo Novo dos Parecis e Sapezal apresentaram um escore de 11 e 14, respectivamente, indicando que na ocupação dos territórios de produção nesses municípios a produção local/regional de alimentos é inviabilizada pela produção de commodities, afetando a soberania alimentar do território. Entre os municípios estudados, apenas Sapezal dispõe de legislação municipal de segurança alimentar e Nutricional, mas não dispõe de Conselho Municipal e Plano Municipal de Segurança Alimentar e Nutricional.

O município de Campos de Júlio apresenta maior área destinada à produção de alimentos e espaços destinados à venda direta, apesar de haver concomitância com grandes áreas de produção de commodities. Ainda assim, observa-se que o município apresenta restrição na produção local de alimentos, devido à ocupação hegemônica dos territórios de produção pelas monoculturas de commodities agrícolas.

Tal ocupação expressa as dificuldades de se definirem os próprios sistemas alimentares. Refletem, ainda, o uso intensivo e desigual da terra para as monoculturas, cujos impactos do modelo produtivo, como o uso intensivo de agrotóxicos e fertilizantes químicos, comprometem a produção local, afetando a soberania alimentar na região.

\section{Discussões}

Entre as características do conceito soberania alimentar, o perfil de produção representa uma importante categoria de análise, por meio do qual é possível identificar a hegemonia do modelo monocultural e de toda a cadeia do agronegócio nos municípios estudados, evidenciando a opção pela reprimarização da agricultura de exportação ${ }^{24}$ e dependência de produtos de outros estados para abastecimento interno.

Os três municípios estão entre as 50 cidades de maior Produto Interno Bruto (PIB) relacionado ao agronegócio em nível nacional, onde Sapezal ocupa o $5^{\circ}$ lugar, com R \$ 845,9 milhões, Campo Novo dos Parecis o $6^{\circ}$ lugar, com R \$ 811,3 milhões, e Campos de Júlio em $40^{\circ}$ lugar, com $\mathrm{R} \$ 433,2$ milhões de reais, com relação aos valores adicionados brutos da Agropecuária ${ }^{25}$. Apesar disso, observa-se concentração de renda e a coexistência de riqueza e situações de vulnerabilidade social, mesmo entre aqueles que trabalham diretamente no agronegócio. Essa riqueza concentrada não permanece no território, uma vez que a produção de commodities é predominantemente voltada à exportação e grande parte das empresas que compõem a cadeia do agronegócio representa o capital estrangeiro ${ }^{26}$.

A opção por não taxar produtos primários para exportação contribui para a definição do território para produção em larga escala de commodities agrícolas para exportação, amparada pela Lei Complementar $n^{\circ} 87$, de 13 de setembro de 1996 - Lei Kandir ${ }^{27}$, que assegura a desoneração do Imposto sobre Circulação de Mercadorias Serviços (ICMS) para os produtos primários e industrializados semielaborados e serviços destinados à exportação. Tal condição vulnerabiliza a oferta de políticas públicas no estado de Mato Grosso, com repercussões importantes sobre o setor saúde, uma vez que o estado deixa de arrecadar tributos oriundos dessas desonerações.

Segundo Acserald ${ }^{\mathbf{2 8}}$, a mudança do papel do Estado como indutor do desenvolvimento de regiões periféricas para fomentador da economia primária de exportação contribuiu para desarticular espaços e para o surgimento de tensões no pacto federativo. Além dos ônus social e ambiental decorrentes do processo produtivo, que permanecem nesses territórios como 'passivo ambiental', os efeitos negativos sobre os sistemas de saúde são observados pela insuficiência de investimentos estruturais nas regiões estudadas.

Para Breilh, o conceito de acumulação por pilhagem, a despeito da mais-valia, amplia-se na atualidade a partir de dois fenômenos: a crescente característica tecnológica da sociedade da informação e a mudança do modelo da acumulação de capital ${ }^{8}$, que levam a um perfil de dominação dos países menos desenvolvidos, 
seus povos e territórios. Ainda, segundo o autor, a pilhagem determina processos de transnacionalização agrícola, monopolização da terra, perda de soberania, desagrarização do campo, perda de direitos humanos, ambientais e conversão dos direitos e dos recursos naturais em mercadorias ${ }^{8}$.

A percepção da produção local, seus aspectos singulares e particulares, e a evidência de uma dependência marcada por instabilidades do mercado financeiro, capacidades de produção de commodities e pressões ambientais nos territórios são percebidas nas falas, que, por um lado, reconhecem que esse modelo produtivo traz maior renda, mas também traz consequências e riscos, fatores protetores e destrutivos ${ }^{29}$, por meio da exposição aos riscos de contaminação às épocas de plantio, pulverização de agrotóxicos e colheita. Ao mesmo tempo, sentem a imposição da dependência do trabalho e da renda, as dificuldades de produção local, afetando a reprodução social e os modos de vida.

A despeito das diferenças existentes entre os diversos agentes, eles vivem em comum certas experiências, como, por exemplo, a subordinação ao mercado distante ${ }^{30}$, que se expressa tanto na comercialização das commodities produzidas localmente quanto na dependência de alimentos provenientes de outros estados para abastecer a região, características do processo de desterritorialização da produção e dos modos de vida. Nesse sentido, o estudo de sistemas alimentares na ocupação dos espaços de produção agrícola pode contribuir para a promoção de territórios saudáveis e sustentáveis.

Seufert, Ramankutty e Foley ${ }^{31}$, em uma metanálise de sistemas convencionais e orgânicos em diferentes países com condições de clima e de manejo específicos, concluem que os rendimentos e benefícios de sistemas familiares de produção orgânica melhoram à medida que são incentivados por pesquisas, desenvolvimento de técnicas e tecnologias de produção e distribuição em circuitos locais e regionais, com reais impactos sobre a melhora dos ambientes e da saúde das populações. Tais evidências foram também apresentadas por Reganold e Wachter ${ }^{32}$, que analisaram o desempenho da agricultura familiar à luz de quatro principais métricas de sustentabilidade: produtividade, impacto ambiental, viabilidade econômica e bem-estar social, e concluíram que, apesar de produzir rendimentos mais baixos, a agricultura familiar orgânica tende a ser mais rentável do ponto de vista econômico, pois oportuniza a distribuição equitativa da renda, é sustentável, produz alimentos mais nutritivos em termos de composição nutricional e sem resíduos químicos, oferece mais serviços ecossistêmicos e benefícios sociais, em comparação com os sistemas convencionais de produção agrícola. Os autores ainda afirmam que sistemas locais de produção e abastecimento pautados em agricultura orgânica e outras formas de produção inovadoras têm potencial de abastecer um número maior de pessoas e necessitam de investimentos em políticas públicas para promover seu desenvolvimento e implementação.

Nigli33 afirma que o maior desafio para a agricultura é reduzir as compensações entre produtividade e sustentabilidade em longo prazo, sendo os sistemas locais de produção familiar e orgânica as formas de produzir e distribuir os alimentos que têm potencial de garantir o futuro da produção sustentável de alimentos. $\mathrm{O}$ mesmo foi reafirmado por Pradhan et al. ${ }^{34}$, que avaliaram por 03 anos a produtividade dos sistemas de produção que utilizaram consorciação e cobertura de culturas com sistemas convencionais de monocultivos, concluindo que, em longo prazo, a agricultura sustentável tem potencial de recuperar solos e água, promovendo maior retenção de nutrientes nos alimentos e produtividade equivalente e maior que os sistemas convencionais de produção.

Estudo realizado por Alencar et al. ${ }^{35}$, avaliando sistemas agrícolas convencionais e de produção familiar orgânica, evidenciou que as interações agricultor-meio ambiente, no sistema de produção familiar, geraram 
melhoria da qualidade de vida das famílias, em contraposição ao sistema convencional, caracterizado pelo uso intensivo de agrotóxicos e pela grande dependência de adubos químicos, onde prevalece o interesse em obter a máxima produção sem preocupação com o ambiente. Tal condição se reflete no contato contínuo com agrotóxicos, margens de lucros restritivas e redução da fertilidade natural dos solos cultivados sob esse sistema.

Com relação aos circuitos locais de produção e distribuição de alimentos, Darolt et al. ${ }^{36}$ analisaram redes alternativas no Brasil e na França. Como resultado, apresentaram uma tipologia, as características e a organização dos circuitos curtos de comercialização, ressaltando que os sistemas alternativos são diversificados e dinâmicos, sendo uma opção social, econômica e ambiental para a agricultura familiar, fortalecendo os mercados locais e reconectando produtores e consumidores. Em ambos os países, as iniciativas bem-sucedidas em sistemas alternativos acontecem em locais onde existem formas de coordenação em rede e parcerias entre o poder público, entidades não governamentais, empresas, organizações de agricultores e consumidores ${ }^{36}$.

Por outro lado, a monopolização do território é uma estratégia desenvolvida pelas empresas de comercialização e/ou processamento industrial da produção agropecuária, que não necessariamente produzem, mas controlam a circulação das mercadorias na economia globalizada ${ }^{30}$, ou seja, monopolizam a produção, sem precisar territorializar os monopólios ${ }^{37}$, controlando o processamento e a comercialização das mercadorias. É o caso das grandes corporações de agrotóxicos, fertilizantes e maquinários, produção e comercialização de sementes transgênicas e controle de patentes e as Tradings, responsáveis por negociar as commodities nos mercados internacionais. Essas empresas atuam nas chamadas estratégias de originação da commoditie, aliando-se a empresas nacionais na exploração de territórios de produção. Os capitalistas nacionais ficam, então, com status de proprietários das terras, mas a exploração do capital industrial, via commodities, é internacional ${ }^{37}$.

As estratégias de legitimação desse modelo encontram voz nos discursos de desenvolvimento econômico local e regional, mas sustentam um número limitado de empresas transnacionais que monopolizam a circulação de mercadorias, ditam as regras econômicas dos mercados e influenciam hábitos e práticas alimentares, por meio de um processo de homogeneização e tipificação do consumo de alimentos rápidos, ultraprocessados, altamente industrializados ou contaminados com resíduos de agrotóxicos.

\section{Considerações finais}

As discussões acerca de um modelo produtivo e suas repercussões em um território como a Bacia do Rio Juruena perpassam a ocupação dominante pelas monoculturas e estruturas relativas à cadeia produtiva do agronegócio, em detrimento de espaços destinados à produção de alimentos e à agricultura familiar policultural, e expressam um fenômeno evidenciado em grande parte do território brasileiro.

Apesar das elevadas taxas de PIB e grandes extensões de terras agriculturáveis, a concentração de renda e de terras é um fenômeno evidente na região e reflete a realidade nacional. $O$ estudo do território contribui para a discussão da vigilância em saúde na perspectiva da vigilância do desenvolvimento. O modelo de produção e reprodução do agronegócio e seus processos de acumulação repercutem nos modos de obtenção e consumo, na saúde das populações expostas, na destruição ambiental progressiva dos ambientes, das águas e dos alimentos. Por outro lado, a promoção de espaços destinados à produção familiar agroecológica e o incentivo aos circuitos de comercialização local e regional potencializam as economias locais, promovem maior disponibilidade de alimentos saudáveis nas cidades, reduzindo a dependência de alimentos produzidos em outros locais, e contribuem positivamente para 
a sustentabilidade e a saúde dos territórios. Assim, é importante garantir aos agricultores familiares o acesso à terra, à escolha do modelo produtivo, bem como às condições de produção e comercialização de seus produtos.

$\mathrm{O}$ indicador proposto apresenta variações internas aos índices nos três municípios, demonstrando tendência de maior impacto, conforme aumenta a produção de commodities agrícolas. No entanto, o estudo apresenta limitações por evidenciar uma realidade de um território agrícola específico, necessitando de novos estudos em diferentes regiões de produção agrícola, além da inclusão de indicadores como contaminação da água de consumo, de alimentos com resíduos de agrotóxicos e a avaliação da implantação da vigilância em saúde de populações expostas aos agrotóxicos nos municípios.

Considera-se, assim, que a métrica apresentada evidencia e dimensiona a ameaça de redução na disponibilidade de alimentos saudáveis para consumo humano em um dado território, posto que a pressão negativa na soberania alimentar exercida pela extensão das áreas de produção voltadas às monoculturas foi evidenciada pelo índice proposto.

\section{Colaboradores}

Montanari-Corrêa ML (0000-0001-78120182)* e Pignati WA (0000-0001-9178-6843)* participaram igualmente de todas as etapas de elaboração do artigo: concepção do estudo, coleta, organização, interpretação e análise dos dados e redação. Pignatti MG (0000-00017942-3847)* e Machado JMH (0000-00021176-1919)* participaram da interpretação, discussão dos dados e revisão crítica do artigo. Lima FANS (0000-0001-5677-2390)* participou da coleta, análise, interpretação e discussão dos dados. Todos os autores aprovaram a versão final do manuscrito.

\section{Referências}

1. Wittman H. Reconnecting agriculture \& the environment: food sovereignty \& the agrarian basis of ecological citizenship. In: Wittman H, Desmarais AA, Wiebe N, editores. Food Sovereignty. Reconnecting Food, Nature and Community. Vancouver: Fernwood Publishing; 2010. p. 91-105.

2. Brasil. Lei $\mathrm{n}^{\circ} 11.346$, de 15 de setembro de 2006. Cria o Sistema Nacional de Segurança Alimentar e Nutricional SISAN com vistas em assegurar o direito hu- mano à alimentação adequada e dá outras providências. Diário Oficial da União. 16 Set 2006.

3. Brasil. Câmara Interministerial de Segurança Alimentar e Nutricional. Plano Nacional de Segurança Alimentar e Nutricional (PLANSAN 2016-2019). Brasília, DF: CAISAN; 2016.

4. Segall-Corrêa AM, Perez-Escamilla R, Marin-Leon L, et al. Evaluation of household food insecurity in
${ }^{*}$ Orcid (Open Researcher and Contributor ID). 
Brazil: validity assessment in diverse sociocultural settings. In: Ortega J, organizador. Iniciativa América Latina sin Hambre: articulos premiados en el dia Mundial de la Alimentación. [local desconhecido]: FAO; 2007. [acesso em 2018 nov 20]. Disponível em: http://bvssan.incap.int/local/file/PubNut-Per\%C3\%BA/texcom/nutricion/memredsan.pdf.

5. Breilh J. Hacia uma redefinicion de La Soberania Agraria: Es Posible La Soberania Alimentaria sin Cambio Civilizatorio y Bioseguridad? In: Bezerra I, Perez-Cassarino J, organizadores. Soberania Alimentar (SOBAL) e Segurança Alimentar e Nutricional (SAN) na América Latina e Caribe. Curitiba: Editora UFPR; 2016. p. 55-68.

6. Azevedo E. Alimentação, sociedade e cultura: temas contemporâneos. Sociologias. 2017; 19 (44):276-307.

7. Franco CR, Pelaez VA. (Des) Construção da Agenda Política de Controle de Agrotóxicos no Brasil. Ambient. Soc. 2016. 19 (3): 215-232.

8. Breilh J. Pilhagens, Ecossistemas e Saúde. In: Miranda AC, Barcellos C, Moreira J, organizadores. Território, ambiente e saúde. Rio de Janeiro: Fiocruz; 2008.

9. Thomaz Junior A. O Tecido social do Trabalho, a produção de alimentos versus agronegócio e luta de classes num ambiente de embates e debates. In: Lourenço EAS, Navarro VL, organizadores. O Avesso do Trabalho III: Saúde do Trabalhador e questões contemporâneas. São Paulo: Outras Expressões; 2013. p. 367-393.

10. Maele-Fabry VAN, Lantin AC, Hoet P, et al. Childhoodleukaemia and parental occupational exposure to pesticides: a systematic review and meta-analysis. Cancer causes control. 2010; 21(6):787-809.

11. Carneiro F, Giraldo L, Pignati WA, et al. Dossiê ABRASCO: um alerta sobre os impactos dos agrotóxicos na saúde. Rio de Janeiro: EPSJV; 2015.

12. Patel R. What Does Food Sovereignty Look Like? In: Wittman H, Desmarais AA, Wiebe N, organizadores.
Food Sovereignty: Reconnecting Food, Nature and Community, Halifax: Fernwood; 2010.

13. Ribeiro H, Jaime PC, Ventura D. Alimentação e Sustentabilidade. Estud. av. 2017; 31(89):185-198.

14. Sauer S. Agricultura Familiar versus agronegócio: a dinâmica sociopolítica do campo brasileiro. Brasília: Embrapa Informação Tecnológica; 2008. 73 p.

15. Instituto Brasileiro de Geografia e Estatística. Censo agropecuário 2006. Rio de Janeiro: IBGE; 2006. p. 777.

16. Bardin L. Análise de conteúdo. Lisboa: Edições 70; 2011.

17. Instituto Brasileiro de Geografia e Estatística. Sistema IBGE de Recuperação Automática [internet]. Rio de Janeiro: IBGE; 2016. [acesso em $2018 \mathrm{dez}$ 10]. Disponível em: https://sidra.ibge.gov.br/pesquisa/pam/ tabelas.

18. Instituto Brasileiro de Geografia e Estatística. Pesquisa de Orçamentos Familiares POF 2008-2009: análise do consumo alimentar pessoal no Brasil/IBGE, Coordenação de Trabalho e Rendimento. Rio de Janeiro: IBGE; 2011. 150 p.

19. Pignati W, Lima FANS, Lara SS, et al. Distribuição espacial do uso de agrotóxicos no Brasil: uma ferramenta para a vigilância em saúde. Ciênc. Saúde Colet. 2017; 22(10):3281-3293.

20. Brasil. Ministério da Saúde, Secretaria de Vigilância em Saúde, Departamento de Vigilância em Saúde Ambiental e Saúde do Trabalhador. Saúde Ambiental: Guia Básico para Construção de Indicadores. Brasília: Ministério da Saúde; 2011. 124 p.

21. Instituto Brasileiro de Geografia e Estatística. Censo agropecuário 2017 - Resultados Preliminares [internet]. Rio de Janeiro: IBGE; 2017. [acesso em 2018 ago 8]. Disponível em: https://censos.ibge.gov.br/ agro/2017/templates/censo_agro/resultadosagro/ index.html. 
22. Pignati WA, Machado JMH, Cabral FM, et al. Acidentes rurais ampliados: o caso das "chuvas" de agrotóxicos sobre a cidade de Lucas do Rio Verde, MT. Ciênc. Saúde Colet. 2007; 12(1):105-114.

23. Brasil. Lei $n^{\circ} 11.947$, de 16 de junho de 2009. Dispõe sobre o atendimento da alimentação escolar e do Programa Dinheiro Direto na Escola aos alunos da educação básica e dá outras providências. Diário Oficial da União. 17 Jun 2009.

24. Medina G, Ribeiro GG, Brasil EM. Participação do capital brasileiro na cadeia produtiva da soja: lições para o futuro do Agronegócio Nacional. Rev. Econ. Agroneg. 2015; 13(1,2,3):1-36.

25. Instituto Brasileiro de Geografia e Estatística. Perfil dos Estados e Municípios Brasileiros - 2014. [internet]. Rio de Janeiro: IBGE; 2014. [acesso em 2018 ago 8]. Disponível em: https://ww2.ibge.gov.br/home/estatistica/economia/perfilmunic/2014/default.sht.

26. Mendonça ML. O Papel da Agricultura nas Relações Internacionais e a Construção do Conceito de Agronegócio. Contexto int. 2015; 37(2):375-402.

27. Brasil. Lei Complementar $n^{\circ} 87$, de 13 de setembro de 1996. Dispõe sobre o imposto dos Estados e do Distrito Federal sobre operações relativas à circulação de mercadorias e dá outras providências. (Lei Kandir). Diário Oficial da União. 14 Set 1996.

28. Acserald H. Sustentabilidade, Território e Justiça Ambiental no Brasil. In: Miranda AC, Barcellos C, Moreira J, organizadores. Território, ambiente e saúde. Rio de Janeiro: Fiocruz; 2008.

29. Breilh J. Epidemiologia Crítica: Ciência Emancipadora e Interculturalidade. Rio de Janeiro: Fiocruz; 2006. 317 p.
30. Santos M. Por uma outra globalização: do pensamento único à consciência universal. 6. ed. Rio de Janeiro: Record; 2001.

31. Seufert V, Ramankutty N, Foley JA. Comparing the yields of organic and conventional agriculture. Nature. 2012; 485(7397):229-232.

32. Reganold JP, Wachter JM Organic agriculture in the twenty-first century. Nat Plants. 2016; 2(2):1-7.

33. Pradhan A, Idol T, Roul PK. Conservation Agriculture Practices in Rainfed Uplands of India Improve Maize-Based System Productivity and Profitability. Front Plant Sci. 2016; 7(1008):1-12.

34. Niggli U. Sustainability of organic food production: challenges and innovations. Proc Nutr Soc. 2015; 74(1):83-88.

35. Alencar GV, Mendonça ES, Oliveira TS, et al. Percepção ambiental e uso do solo por agricultores de sistemas orgânicos e convencionais na Chapada da Ibiapaba, Ceará. Rev. Econ. Sociol. Rural [internet]. 2013 [acesso em 2018 ago 8]; 51(2):217-236. Disponível em: http://dx.doi.org/10.1590/S010320032013000200001.

36. Darolt MR, Lamine C, Brandenburg A, et al. Redes alimentares alternativas e novas relações produção-consumo na França e no Brasil. ambient. soc. [internet]. 2016 [acesso em 2018 ago 8]; 19(2):122. Disponível em: http://dx.doi.org/10.1590/1809-4422asoc121132v1922016.

37. Oliveira AU. A Mundialização da Agricultura Brasileira. São Paulo: Iandé Editorial; 2016. 545 p.

Recebido em 11/03/2019

Aprovado em 25/10/2019

Conflito de interesses: inexistente

Suporte financeiro: não houve 